\title{
ALFABETIZAÇÃO CIENTÍFICO-TECNOLÓGICA PARA QUÊ?
}

\author{
Décio Auler ${ }^{1[1]}$ \\ Depto. Metodologia de Ensino - UFSM \\ auler@ce.ufsm.br \\ Demétrio Delizoicov \\ Depto. Metodologia de Ensino - UFSC \\ demetrio@ced.ufsc.br
}

\section{RESUMO}

A Alfabetização Científico-Tecnológica (ACT), cada vez mais, tem sido postulada enquanto dimensão fundamental numa dinâmica social crescentemente relacionada ao desenvolvimento científico-tecnológico. Contudo, o rótulo ACT abarca um espectro bastante amplo de significados. Os objetivos balizadores são diversos e difusos. Neste trabalho, discutese ACT segundo duas perspectivas, denominadas de reducionista e ampliada. A reducionista, em nossa análise, desconsidera a existência de construções subjacentes à produção do conhecimento científico-tecnológico, tal como aquela que leva a uma concepção de neutralidade da Ciência-Tecnologia. Relacionamos a esta compreensão de neutralidade os denominados mitos: superioridade do modelo de decisões tecnocráticas, perspectiva salvacionista da Ciência-Tecnologia e o determinismo tecnológico. A perspectiva ampliada, proposta neste trabalho, busca a compreensão das interações entre Ciência-TecnologiaSociedade (CTS), associando o ensino de conceitos à problematização desses mitos.

Palavras chave: Alfabetização Científico-Tecnológica, Ciência-Tecnologia-Sociedade.

\section{ABSTRACT}

Increasingly, technological-scientific literacy has been postulated while fundamental dimension in the social dynamics related to technological-scientific development. However, technological-scientific literacy covers a wide spectrum of meanings. The objectives are diverse and diffuse. This paper discusses technological-scientific literacy according to reductionistic and broad perspectives. The reductionism, in our analysis, does not consider the existence of constructions that underlie the production of technological-scientific knowledge, such as the one that leads to the conception of science and technology neutrality. This conception can be related to myths which are called superiority of technocratic decisions' model, technological-science saving perspective and technological determinism. The broad perspective, proposed in this work, aims to comprehend the interactions among Science-Technology-Society (STS), associating the learning of concepts to the myths discussions.

Key words: Technological-scientific literacy, Science-Technology-Society.

${ }^{1[1]}$ Doutorando em Educação - Ensino de Ciências Naturais, UFSC. Bolsista da CAPES. 


\section{INTRODUÇÃO}

Possivelmente potencializada pelos recentes avanços da Ciência-Tecnologia (CT), particularmente no campo da clonagem-engenharia genética, ganha vigor a idéia da Alfabetização Científico-Tecnológica (ACT). Parte-se da premissa de que a sociedade seja analfabeta científica e tecnologicamente e que, numa dinâmica social crescentemente vinculada aos avanços científico-tecnológicos, a democratização desses conhecimentos é considerada fundamental.

Contudo, o rótulo Alfabetização Científica e Tecnológica abarca um espectro bastante amplo de significados traduzidos através de expressões como popularização da ciência, divulgação científica, entendimento público da ciência e democratização da ciência. Os objetivos balizadores são diversos e difusos. Vão desde a busca de uma autêntica participação da sociedade em problemáticas vinculadas à CT, até aqueles que colocam a ACT na perspectiva de referendar e buscar o apoio da sociedade para a atual dinâmica do desenvolvimento científico-tecnológico. Em outros termos, há, por um lado, encaminhamentos mais próximos de uma perspectiva democrática e, por outro, encaminhamentos que direta ou indiretamente respaldam postulações tecnocráticas.

Este trabalho apresenta uma síntese de categorias empregadas em uma pesquisa em andamento (Auler, 2001), a qual busca encaminhamentos, no processo de formação de professores de ciências e, conseqüentemente, para o ensino de ciências, no sentido de contemplar interações entre Ciência-Tecnologia-Sociedade (CTS). No decorrer dessa pesquisa, foi-se constatando a necessidade da explicitação e clarificação de algumas construções subjacentes à produção do conhecimento científico e tecnológico, realizadas historicamente, as quais, vinculadas a uma concepção que atribui neutralidade a CT, expressam, segundo análise apresentada neste trabalho, idéias pouco consistentes sobre a atividade científico-tecnológica. Nesse sentido, essas construções, que se tornaram categorias balizadoras para análise, foram aqui denominadas de mitos, considerando que, tal qual um mito, em vários contextos, estão fora do alcance de uma reflexão crítica.

Nesse sentido, realizamos um estudo exploratório inicial no qual buscamos conhecer as compreensões de professores de ciências sobre as interações entre CTS. Os resultados dessa investigação preliminar, apresentados e discutidos no II ENPEC (Auler e Delizoicov, 1999), sinalizaram para a presença, na compreensão desses professores, de aspectos que estamos relacionando a esses mitos.

Três mitos foram particularmente examinados: superioridade do modelo de decisões tecnocráticas, perspectiva salvacionista da CT e o determinismo tecnológico. Sua escolha foi feita levando em conta sua importância para efeito de problematização. Esses três mitos foram encarados como manifestações da concepção de neutralidade da CT. Daí, denominar-se a concepção de neutralidade da CT de "mito original". Refletir, problematizar essas construções não significa, de forma alguma, uma posição anti-ciência e anti-tecnologia. Pelo contrário, contribui, no nosso entender, para a construção de uma imagem mais realista da atividade científico-tecnológica. Além disso, mitos não combinam com postulações democráticas.

Ter como pano de fundo a neutralidade ou a não neutralidade da CT, leva a encaminhamentos muito diferenciados em relação ao ensino de ciências. Concebendo CT 
como neutras, derivando dessa concepção os referidos mitos, pode-se, facilmente, cair em reducionismos relativamente a Alfabetização Científico-Tecnológica. Apresenta-se, a seguir, uma reflexão sobre dois encaminhamentos, distintos, relativamente a ACT, cuja bifurcação centra-se na consideração ou não desses mitos no processo educacional.

\section{OS MITOS}

\subsection{SUPERIORIDADE DO MODELO DE DECISÕES TECNOCRÁTICAS}

Conforme Amilcar Herrera (2000), Uma Das Maneiras Mais Efetivas De Terminar Com Uma Discussão Consiste Em Dizer Que Algo Esta Cientificamente Provado. Segundo Ele, Isso Deixa O Adversario Desarmado. Destaca Que, Em Epocas Passadas, Obtinha-Se O Mesmo Resultado Com A Afirmativa De Que Estava Respaldado Na Biblia.

Para Luján et al. (1996), o cientificismo, sustentáculo da tecnocracia, é lastreado na crença da possibilidade de neutralizar/eliminar o sujeito do processo científico-tecnológico. 0 expert (especialista/técnico) poderia solucionar os problemas sociais de um modo eficiente e ideologicamente neutro. Para cada problema existe uma solução ótima. Portanto, deve-se eliminar os conflitos ideológicos ou de interesse.

O cientificismo, na compreensão de Chassot (1994), pode ser sintetizado por dois "axiomas", quais sejam: a superioridade teórica e prática da ciência para qualquer situação. A nível teórico, seria um conhecimento superior a todos os demais. No campo prático, seria a melhor forma de conhecimento para resolver problemas situados desde o campo técnico até o ético.

No entender de Pacey (1990), a perspectiva tecnocrática refere-se a uma visão de mundo que praticamente não deixa espaço para a democracia nas decisões que afetam a tecnologia, considerando que essa está presa a uma visão de progresso, de resolução de problemas que exclui ambigüidades. A intolerância frente a ambigüidades inviabiliza o debate sobre o futuro: só há uma forma de avançar e o especialista, melhor do que ninguém, pode comandar o processo. A participação pública na escolha entre enfrentamentos possíveis a uma determinada situação, introduz, segundo a perspectiva tecnocrática, um elemento de incerteza, inaceitável nessa visão.

Thuillier (1989) destaca que a ciência é valorizada, na sociedade moderna, como instância absoluta, exatamente como Deus é visto na Igreja. Assim como diziam os padres que queimavam hereges na inquisição "não sou eu, é Deus quem o quer", nossos tecnocratas, ao tomarem decisões, dizem que não são eles os responsáveis, mas a ciência. Destaca Thuillier,

"A tendência da tecnocracia é transferir a 'especialistas', técnicos ou cientistas, problemas que são de todos os cidadãos. (...) Escolhas políticas são transformadas em questões a serem decididas por comitês de especialistas. Não digo que os tecnocratas sejam maus, nem que tomem sempre decisões erradas. Digo que é mau o sistema que Ihes dá esse poder" (Thuillier, 1989:22).

A aparente neutralidade dos tecnocratas provém, segundo Fourez (1995), do fato de que as decisões importantes já foram tomadas quando se adotou determinado paradigma disciplinar ou método interdisciplinar. Ao adotá-los, "aceita-se de maneira cega os seus pressupostos". 


\subsection{PERSPECTIVA SALVACIONISTA DA CT}

$\mathrm{Na}$ concepção tradicional/linear de progresso ${ }^{2[2]}, \mathrm{CT}$, em algum momento do presente ou do futuro, resolverão os problemas hoje existentes, conduzindo a humanidade ao bem-estar social. Duas idéias estão associadas a isso: CT necessariamente conduzem ao progresso e Ciência e Tecnologia são sempre criadas para solucionar problemas da humanidade, de modo a tornar a vida mais fácil.

Contudo, o desenvolvimento científico-tecnológico não pode ser considerado um processo neutro que deixa intactas as estruturas sociais sobre as quais atua. Nem a Ciência e nem a Tecnologia são alavancas para a mudança que afetam sempre, no melhor sentido, aquilo que transformam. O progresso científico e tecnológico não coincide necessariamente com o progresso social e moral (Sachs, 1996).

A idéia de que os problemas hoje existentes, e os que vierem a surgir, serão automaticamente resolvidos com o desenvolvimento cada vez maior da CT, estando a solução em mais e mais CT, está secundarizando as relações sociais em que essa CT é concebida.

Pacey, já citado, argumenta que, em geral, as pessoas remetem os problemas enfrentados pela sociedade como, por exemplo, poluição, para o campo técnico, pensando que a extraordinária capacidade da tecnologia moderna conduzirá a uma "solução apropriada". Mas, segundo ele, esses problemas têm uma componente social. Esperar por uma solução apenas técnica, que não inclua medidas sociais e culturais, "é mover-se em um terreno ilusório". Destaca que a escassez de alimentos e os problemas de energia são transformados em questões estritamente técnicas, ignorando muitos aspectos relativos à organização e a sua aplicação.

Gana (1995) destaca que a situação social e econômica dos países latino-americanos não é produto da acaso. Obedece a uma série de fatores (econômicos, históricos, culturais, políticos, entre outros), internos ao país e externos em suas relações com o resto do mundo. Argumenta que, em nenhum caso, esta situação será eliminada ou atenuada exclusivamente através da inovação tecnológica.

Por exemplo, para reduzir/acabar com a carência alimentar, com a fome, efetivamente, é necessário produzir alimentos em quantidade suficiente. Nesse aspecto, a CT podem contribuir significativamente, aproveitando, inclusive, os avanços da biologia molecular. Contudo, a CT não possuem nenhum mecanismo intrínseco que garanta a distribuição dos alimentos produzidos. CT são fundamentais no campo da produção. Porém, em termos de distribuição, há outras dimensões a serem consideradas.

2[2] Nessa, o desenvolvimento científico (DC) gera desenvolvimento tecnológico (DT), este gerando o desenvolvimento econômico (DE) que determina, por sua vez, o desenvolvimento ou bem-estar social (DS). O modelo tradicional/linear de progresso pode ser então assim representado:
DC (DT DE ( DS (Lujan et al., 1996). 
No entender de Ayarzagüena et al.,

"Chegamos a pensar, em muitas situações, que a única solução para os problemas está na ciência. Esquecemos - ou nos fazem esquecer - que nem todos os problemas são de caráter científico-tecnológico. Em suma, precisamos trabalhar o fato de que mais ciência, mais técnica, não significa, necessariamente, vida melhor para todos" (Ayarzagüena et al. apud Bazzo, 1998:168).

\subsection{DETERMINISMO TECNOLÓGICO}

Segundo Gómez (1997) ${ }^{3[3]}$, há duas teses definidoras do determinismo tecnológico: a) a mudança tecnológica é a causa da mudança social, considerando-se que a tecnologia define os limites do que uma sociedade pode fazer. Assim, a inovação tecnológica aparece como o fator principal da mudança social; b) A tecnologia é autônoma e independente das influências sociais.

$\mathrm{Na}$ análise de Sanmartín (1990), a concepção do determinismo tecnológico não se configurou como algo isolado, mas no âmbito da "superteoria" (superideologia) do progresso. Contrariamente as superteorias da providência divina e da do eterno retorno, que a precederam, nessa o fator tempo não é mais cíclico ${ }^{4[4]}$, mas incorpora a idéia de tempo linear. Caminhamos em direção ao futuro, em direção ao progresso, não há mais volta. Dentre as características dessa superteoria, Sanmartín aponta:

- A sociedade e o ser humano são considerados produtos de uma tecnologia autônoma em seu desenvolvimento;

- A sociedade e o ser humano serão cada vez melhores graças ao acúmulo de inovações tecnológicas. O progresso social é conseqüência do progresso tecnológico;

- Toda inovação tecnológica é boa por si mesma, contribuindo para a geração de riqueza, para o bem-viver, havendo uma relação causal perfeita entre inovação tecnológica e avanço humano;

- Da tecnologia espera-se a construção científica de um mundo sucessivamente melhor.

$\mathrm{Na}$ compreensão de Sanmartín, essa superideologia nutre-se de "mitos propagandísticos", de expressões do tipo: "ou a revolução tecnológica, que nos trará um mundo melhor, ou o estancamento e o retorno às cavernas", símbolo de um passado negativo. Escolher este último significa não trabalhar segundo os novos tempos, o que, por sua vez, pode

\footnotetext{
${ }^{3[3]}$ Gómez (1997) destaca que, na sociedade norte-americana, com altíssimo desenvolvimento tecnológico, foi ganhando corpo uma compreensão determinista da tecnologia, "até aparecer como parte da ideologia dominante na maioria do povo norteamericano".

${ }^{4[4]}$ A superteoria do progresso apresenta o tempo de forma linear, contrariamente a superteoria do eterno retorno (teoria do tempo cíclico). Nesta última, está articulada uma concepção de mundo que contém a crença de que cada ciclo repete em seus detalhes o curso e os acontecimentos do ciclo anterior. Não podia, nessa, frutificar a idéia estrita de progresso. Também na superteoria da providência divina isso era inconcebível.
} 
dar vantagem para nossos competidores. Qualquer questionamento crítico é encarado como irracional, um retorno à era das trevas.

Gómez, já citado, destaca que o avanço tecnológico é uma atividade social, sendo que o curso do mesmo responde à direção imprimida pela sociedade ou por segmentos dessa. Se a tecnologia avança em diversas áreas (agricultura, guerra, etc) e não em outras, isso se deve aos incentivos e recompensas oferecidas. O avanço tecnológico não opera por si mesmo. As mudanças acontecem porque favorecem grupos, sendo que outros grupos oferecem resistências. Influem, no desenvolvimento tecnológico, condições econômicas, políticas e sociais, assim como organizações estatais e privadas. Considera que o endosso ao determinismo tecnológico, consiste numa forma sutil de negar as potencialidades e a relevância da ação humana.

Mesmo sem endossar o determinismo tecnológico, Gana (1995) não cai no outro extremo, o do determinismo social. Acentua que a adoção de determinada tecnologia gera múltiplos resultados, surgindo situações novas, inicialmente não previstas. A configuração de uma nova tecnologia, no "real", dá-se na interação com fatores sociais, culturais e econômicos.

Winner (1987), prefere a expressão "sonambulismo tecnológico" para caracterizar o comportamento conformado, a aceitação passiva da sociedade diante da chamada "marcha do progresso", diante de novos artefatos tecnológicos, sem nenhuma reflexão crítica em relação aos aspectos positivos e negativos dela decorrentes.

Contemporaneamente, no contexto do "caminho único", respaldado pelo discurso do "pensamento único" - "fim da história", "fim das ideologias"-, está havendo um superdimensionamento da tecnocracia em detrimento da democracia. Democracia pressupõe a possibilidade de escolha, de eleição entre várias possibilidades, entre vários caminhos. Por outro lado, a racionalidade tecnocrática sustenta e legitima o pensamento do caminho único. Segundo essa lógica, para cada problema existe uma solução única, ou ótima. Essa racionalidade exclui opções políticas. Nesse contexto, o determinismo tecnológico é reforçado.

\section{ACT NA PERSPECTIVA REDUCIONISTA E AMPLIADA}

A Alfabetização Científica e Tecnológica, no nosso entender, pode ser concebida segundo duas perspectivas, ou seja, o sentido reducionista e o ampliado ${ }^{5[5]}$. Este último, mais próximo de uma concepção progressista de educação. Na perspectiva reducionista, reduz-se a ACT ao ensino de conceitos, ignorando a existência de mitos, como os anteriormente apresentados e discutidos, aspecto que contribui para uma "leitura da realidade" que se poderia argumentar como sendo bastante ingênua. Reduzir ACT ao ensino de conceitos, bem como trabalhar na perspectiva de entender artefatos tecnológicos e científicos numa dimensão apenas técnica, internalista, pode contribuir para manter ocultos mitos ligados à CT.

Nessa perspectiva reducionista, espera-se que os "conteúdos operem por si mesmos" ou como um fim em si. Na ampliada, os conteúdos são considerados como meios para a compreensão de temas socialmente relevantes.

${ }^{5[5]}$ Fourez (1999), referindo-se a ACT, utiliza as expressões "sentido restrito" e "sentido amplo". 


\subsection{PERSPECTIVA REDUCIONISTA}

A perspectiva, aqui considerada reducionista, parece conter aproximações com o denominado modelo de "déficit cognitivo", utilizado para a avaliação sobre o entendimento público da ciência, citado e discutido por Rosa (2000). Apoiada em análises de vários autores, principalmente Wynne e Irwin, destaca que, segundo esse modelo, a alfabetização em CT estabelece como meta a transmissão unidirecional do conhecimento científico, estando implícito, nessa forma de ACT, uma tentativa de preservar e, se possível, ampliar o apoio recebido pela ciência. Fundamenta-se numa postura pouco crítica em relação às implicações da CT na sociedade. Segundo esses autores, citados por Rosa, nesse modelo, estão implícitos três princípios básicos:

a) O público é ignorante sobre questões científicas e tecnológicas. As controvérsias públicas sobre questões científicas e técnicas são atribuídas a um entendimento inadequado, por parte do público, e não devido ao funcionamento da ciência em si;

b) A visão de mundo oferecida pela ciência é considerada única e privilegiada, constituindo um fator essencial para a melhoria das condições humanas e ambientais;

c) A ciência é retratada como uma atividade neutra, desprovida de valores. As condições sob as quais o conhecimento científico é construído e validado não são questionadas e à ciência é atribuído um caráter de atividade desprovida de ambigüidades e contradições.

Irwin e Wynne, mencionados por Rosa, alertam que, nessa visão o que se pretende é, na verdade, evitar a necessária problematização da ciência, dos cientistas e das instituições científicas. Ao atribuir um caráter redentor à $\mathrm{CT}^{6[6]}$, aspecto implícito nessa concepção de $\mathrm{ACT}$, representa um esforço, por parte das instituições científicas, em recuperar seu papel social e sua legitimação.

Alternativamente ao modelo de déficit cognitivo, Rosa apresenta e discute o modelo interacionista, o qual abarca concepções que problematizam a CT e suas instituições, bem como colocam em discussão do que seja o entendimento público sobre as mesmas. Entendemos que esse modelo interacionista pode ser aproximado ao que temos denominado de ACT numa perspectiva ampliada.

\subsection{PERSPECTIVA AMPLIADA}

Nessa perspectiva ampliada de ACT, aproximações com o referencial freiriano (Freire, 1987, 1996) podem contribuir para a superação dos mitos. Particularmente no processo de formação de professores, a perspectiva problematizadora e dialógica permite estruturar um trabalho pedagógico (Pernambuco, 1993; Delizoicov, 1991) com a finalidade de obter e problematizar a visão dos licenciandos e licenciados sobre as relações CTS. Para Freire, educação relaciona-se com "conhecimento crítico da realidade", com "uma leitura crítica do mundo". Esse se constitui no ponto central dessa aproximação: Para "uma leitura crítica do mundo", para o "desvelamento da realidade", a problematização, a desmistificação dos mitos construídos, historicamente, sobre as interações entre Ciência-Tecnologia-Sociedade (CTS), é

\footnotetext{
${ }^{6[6]}$ Esse caráter redentor, supostamente atribuído à $\mathrm{CT}$, pode ser cotejado com o mito que nós denominados de perspectiva salvacionista da CT.
} 
fundamental. A postura fatalista, a percepção ingênua da realidade está vinculada a esses mitos que, dentre outras características, são paralisantes.

Os fatalismos, aos quais Freire constantemente faz referência, manifestam-se, hoje, por exemplo, sob a forma de determinismos tecnológicos, em suas várias manifestações - "não podemos deter o avanço tecnológico"; "o desemprego no mundo é uma fatalidade do fim do século". A superação de uma percepção ingênua e mágica da realidade exige, cada vez mais, uma compreensão dos sutis e delicados processos de interação entre CTS. Exige um "desvelamento" dos discursos ideológicos vinculados à CT, manifestos, muitas vezes, na defesa da entrega do destino, da sociedade, à tecnocracia. Uma realidade, uma sociedade, em seu conjunto, aparentemente imobilizada, anestesiada pelo discurso pragmático, vinculado ao progresso científico e tecnológico, de não perder o trem da história.

Freire sempre destacou a centralidade, em seu fazer educacional, da dialogicidade e da problematização. Dialógico no sentido do respeito, do diálogo entre os saberes do educando e do educador, aspecto fundamental para a problematização de situações reais, contraditórias vividas pelo educando. Coerente com essas dimensões, passou a fazer críticas agudas à educação que denominou de bancária, postulando e praticando, em substituição a essa, a educação problematizadora ${ }^{7[7]}$. Na bancária, constituindo-se num ato de depositar e consumir idéias, gera-se imobilismo, atitudes reacionárias, concebendo o futuro como pré-dado. Os alunos são objetos passivos da ação de outros, conformando uma postura fatalista, decorrendo uma percepção ingênua ou mágica da realidade. Em síntese, dessa forma, o processo educacional fomenta a "cultura do silêncio".

Contrariamente, a educação dialógica e problematizadora questiona essa realidade percebida de forma ingênua/mágica. Nessa concepção, a realidade é concebida de forma dinâmica, reforçando a mudança. O ser humano, como um sujeito histórico. O aprendizado deve estar intimamente associado à compreensão crítica da situação real vivida pelo educando. Nas palavras de Freire,

"E não se diga que, se sou professor de biologia, não posso me alongar em considerações outras, que devo apenas (grifo do autor) ensinar biologia, como se o fenômeno vital pudesse ser compreendido fora da trama históricosocial, cultural e política. Como se a vida, a pura vida, pudesse ser vivida de maneira igual em todas as suas dimensões favela, no cortiço ou numa zona feliz dos "Jardins" de São Paulo. Se sou professor de biologia, obviamente, devo ensinar biologia, mas, ao fazê-lo, não posso secioná-lo daquela trama." (Freire, 1992: 79).

No entender de Freire, a alfabetização não pode se configurar como um jogo mecânico de juntar letras. Alfabetizar muito mais do que ler palavras, deve propiciar a "leitura do mundo". Leitura da palavra e "leitura do mundo" devem ser consideradas numa perspectiva dialética. Alfabetizar não é apenas repetir palavras, mas dizer a sua palavra. Contemporaneamente, cada vez mais, a dinâmica social está relacionada aos avanços no campo científico e tecnológico.

\footnotetext{
${ }^{7[7]} \mathrm{Na}$ prática problematizadora, propõe-se aos educandos sua situação de vida como problema. Propõe-se a eles sua situação como incidência do ato reflexivo.
} 
Nesse sentido, consideramos que uma reinvenção da concepção freiriana deve incluir uma compreensão crítica sobre as interações entre Ciência-Tecnologia-Sociedade (CTS), dimensão fundamental para essa "leitura do mundo" contemporâneo. Um avanço para além de Freire, tendo-o como inspirador.

O próprio Freire manifestou esta necessidade:

"Nunca, talvez, a frase quase feita - exercer o controle sobre a tecnologia e pô-la a serviço dos seres humanos - teve tanta urgência de virar fato quanto hoje, em defesa da liberdade mesma, sem a qual o sonho da democracia se esval" (Freire, 1992: 133).

Qual o papel dos conteúdos, nessa concepção progressista, postulada para o ensino de ciências naturais? Delizoicov (1991) argumenta que o grande alvo das críticas de Freire é a educação bancária e não o desenvolvimento de conhecimentos "universais". Salienta que a acusação de que a concepção freiriana leva ao espontaneísmo, ao esvaziamento de conteúdos, deve-se a omissão de algo central em sua obra: a investigação temática ${ }^{8[8]}$ e 0 processo de redução temática.

Poder-se-ia considerar o desenvolvimento de "conhecimentos universais" como invasão cultural? Para Freire,

"Se não é possível defender uma prática educativa que se contente em girar em torno do 'senso comum', também não é possível aceitar a prática educativa que, zerando o 'saber de experiência feito', parta do conhecimento sistematizado do(a) educador(a)" (Freire, 1992: 59).

Condena o desrespeito ao saber de senso comum, defendendo a necessidade que têm, educadores e educadoras progressistas, de jamais subestimar ou negar os "saberes de experiência feitos", com que os educandos chegam à escola. Considera que não é possível "tentar superá-lo sem, partindo dele, passar por ele". Assim, a "miopia", ou seja, subestimar ou negar os "saberes de experiência feitos" com que os educandos chegam à escola, "constituindo-se em obstáculo ideológico, provoca o erro epistemológico". Para ele

"No fundo, isso tem a que ver com a passagem do conhecimento ao nível do 'saber de experiência feito, do senso comum, para o conhecimento resultante de procedimentos mais rigorosos de aproximação aos objetos cognoscíveis. $E$ fazer essa superação é um direito que as classes populares têm" (Freire, 1992: 84).

Entendemos que os conteúdos ${ }^{9[9]}$, se desenvolvidos na perspectiva da compreensão de temáticas locais, significativas, possuem um potencial papel transformador ${ }^{10[10]}$. Além disso, é

\footnotetext{
${ }^{8[8]}$ Para uma compreensão mais ampla desse processo, pode-se consultar Pernambuco (1993) e Delizoicov (1991, cap. 3).

${ }^{9[9]}$ Menezes (1988 ), físico-educador argumenta que o ensino de Física, em todos os níveis, é excessivamente centrado no instrumental teórico, em detrimento da reflexão sobre o universo natural e prático, devendo ser
} 
fundamental a problematização dos mitos subjacentes aos conteúdos, relativamente às interações entre CTS.

O desenvolvimento de conteúdos, associado à problematização de mitos, conforme discussão anterior, tem respaldo em Freire, quando esse postula que

"numa escola de governo progressista ${ }^{1111]}$ se torna imperioso o ensino dos conteúdos, a que se junte a leitura crítica e desocultante da realidade" (Freire, 1991: 53).

Em síntese, concebemos ACT ampliada como a busca da compreensão sobre as interações entre Ciência-Tecnologia-Sociedade. Em outros termos, o ensino de conceitos associado ao desvelamento de mitos vinculados à CT. Por sua vez, tal aspecto remete à discussão sobre a dinâmica de produção e apropriação do conhecimento científico-tecnológico.

No Jornal da Ciência (JC), editado pela Sociedade Brasileira para o Progresso da Ciência (SBPC), também comparecem reflexões, realizadas majoritariamente no exterior, preocupadas em alargar os horizontes relativamente a alfabetização científico-tecnológica. Por exemplo, o editor da revista Nature, David Dickson, em entrevista ao JC, questionado sobre a popularização da ciência para o público, declarou que, na sociedade moderna, é irracional esperar que o público geral tenha uma total compreensão da ciência moderna em toda a sua complexidade, ou mesmo que seja capaz de usar esta informação diretamente na condução de sua vida diária. No entanto, segundo ele,

"É essencial que o público entenda de maneira apropriada a natureza do número crescente de decisões políticas na área da ciência - ou que envolvem a ciência que são tomadas em seu nome. (...)Essas decisões não podem ser tomadas por cientistas ou comissões técnicas em encontros com portas fechadas. Cientistas e especialistas técnicos têm um papel crucial no momento de fornecer informações relevantes. Mas, em uma democracia, as decisões devem ser o resultado de um debate aberto e bem informado, e é neste contexto que a popularização da ciência é tão importante." (Dickson, 2001: 12) ${ }^{12[12]}$.

Ao responder um questionamento sobre como a internet poderia ajudar na popularização da ciência, Dikson destaca que a Internet estimula maior transparência no processo de tomada de decisão, "que é o objetivo real da popularização da ciência".

Também, relativamente ao entendimento público da ciência, Enio Candotti ${ }^{13[13]}$ apresenta as principais conclusões do relatório ${ }^{14[14]}$ resultante de um estudo sobre as relações entre

redirecionado no sentido de permitir tanto a "formação de visões-de-mundo quanto a aquisição de conhecimentos úteis à vida".

10[10] Nesse sentido, Delizoicov argumenta que não é qualquer conhecimento "universal" que possui caráter transformador.

${ }^{11[11]}$ Freire refere-se à sua gestão frente a Secretaria Municipal de Educação de São Paulo, de 1989 a 1991.

${ }^{12[12]}$ Entrevista apresentada no Jornal da Ciência (JC), n. 457, 2001.

${ }^{13[13]}$ Jornal da Ciência, n. 453, 2001.

${ }^{14[14]}$ Esse relatório, do parlamento britânico, segundo Candotti, orientou um ciclo de debates coordenado pelo Conselho Britânico em diversas partes do mundo, intitulado Ciência e Sociedade: rumo à democratização da 
ciência e sociedade, realizado por uma comissão criada pelo Parlamento Inglês. Dentre essas, destacamos:

a) "Todo o processo desde a definição dos problemas até a avaliação e implementação das políticas científicas deve ser tornado mais democrático";

b) "A independência dos cientistas e os seus pareceres são questionados em vista de seus fortes laços com instituições privadas que financiam a pesquisa e têm interesses comerciais em seus resultados";

c) "Foi desastrosa a política até agora adotada para promover a compreensão da ciência pelo público através, apenas, do aumento das doses de informação, sem levar em conta o que ele espera, teme ou pensa dos avanços da ciência";

d) "Certezas e incertezas devem ser igualmente valorizadas nas discussões públicas e na divulgação da ciência e de suas aplicações tecnológicas";

e) "É motivo de confusão, no debate público sobre questões de ciência, acreditar que os problemas de risco possam ser reduzidos a um conjunto de questões para as quais a pesquisa científica é capaz de dar respostas não controversas. Na maioria das vezes, na verdade, as questões são complexas. A compreensão científica pode contribuir para uma solução dessas questões, mas em parceria com julgamentos baseados nas atitudes do público, valores e ética".

\section{CONSIDERAÇÕES FINAIS}

Cada vez mais, corporifica-se a idéia da democratização da ciência e tecnologia como pré-requisito para o exercício da cidadania, da democracia. Nesse ponto, situamos uma das principais considerações em relação às reflexões realizadas neste trabalho: levantamos a hipótese de que, ao reivindicar a divulgação, popularização de conhecimentos, fatos, informações, conceitos científicos, com a honesta justificativa de sua imprescindibilidade para o exercício democrático, pode-se contribuir, de fato, para o estrangulamento do exercício pleno da democracia, reforçando postulações tecnocráticas. Fourez ${ }^{15[15]}$ alerta para o fato de que tentar resolver um problema, desvinculando-o das relações sociais em que se configura, de forma apenas técnica, via aumento de conhecimentos técnico-científicos, significa um retorno à tecnocracia.

Colocado de outra forma, na socialização, na democratização de informações, do conhecimento científico e tecnológico, está implícito o risco de que, subjacente a isso, haverá a "socialização", o reforço de mitos, de dogmas, construídos historicamente, incompatíveis como o efetivo exercício da democracia. Mitos, dogmas que podem reforçar a cultura de passividade, característica cultural brasileira, denunciada por vários autores ${ }^{16[16]}$.

ciência. O relatório dessa comissão pode ser encontrado no site <www.parliament.the-statinaryoffice.co.uk/pa/ld199900/ldselect/ldsctech/38/3804.htm>

${ }^{15[15]}$ Análise realizada, por Fourez, em Seminário ocorrido, em outubro de 1999, no Programa de Doutorado em Educação na UFSC.

${ }^{16[16]}$ Vários autores, dentre esses Paulo Freire, têm denunciado que um elemento integrante da cultura, do povo brasileiro, é a passividade, ou a "cultura do silêncio". 
Além disso, em vários contextos, emerge a preocupação com a perda de confiança, da sociedade, na CT, havendo movimentos no sentido de conquistá-la ou reconquistá-la. Nesse sentido, há vários aspectos, no nosso entender, a serem considerados:

a) Não será através de um simples incremento quantitativo de conhecimentos divulgados, popularizados ou democratizados que aumentará essa confiança. Essa lógica aplicada, por exemplo, ao ensino de ciências, pode resultar em efeito contrário;

b) Segundo o biólogo francês Testar ${ }^{17[17]}$, um dos responsáveis pelo nascimento do primeiro bebê de proveta na França, a ciência acabou. "Só existe a tecnociência, uma busca permanente por inovações, alimentada pelo mercado, em nome do progresso". Subtraindo possíveis exageros dessa afirmação, a sociedade, mesmo de forma difusa, progressivamente, parece estar constatando que o atual encaminhamento dado ao desenvolvimento científico e tecnológico está muito mais voltado à lógica do lucro, do que para a satisfação de interesses e necessidades da coletividade. Assim, propiciar, ao conjunto da sociedade, uma participação maior no direcionamento, na definição das prioridades de investigação, na dinâmica de exploração da fronteira do conhecimento científico e tecnológico, não poderia constituir-se num fator fundamental de conquista/reconquista da confiança?;

c) Contudo, para tal, entendemos ser essencial a construção de uma compreensão mais consistente sobre a produção e apropriação do conhecimento científico e tecnológico, aspecto que passa pela problematização de mitos como os citados e discutidos neste trabalho. Esse é, no nosso entender, um dos papéis da ACT, se calcada em objetivos verdadeiramente democráticos.

\section{BIBLIOGRAFIA}

AULER, D. (2001) Interações entre Ciência-Tecnologia-Sociedade no Contexto da Formação de Professores de Ciências. Qualificação de Doutoramento. Florianópolis: CED/UFSC.

AULER, D. e DELIZOICOV. D. (1999) Visões de Professores sobre as Interações entre CiênciaTecnologia-Sociedade (CTS). Resumos, II Encontro Nacional de Pesquisa em Educação em Ciências (II ENPEC). Vallinhos.

BAZZO, W. A. (1998) Ciência, Tecnologia, Sociedade: e o Contexto da Educação Tecnológica. Florianópolis: Ed. UFSC.

CHASSOT, A. (1994) A Ciência através dos Tempos. 8 Impressão. São Paulo: Moderna (coleção Polêmica).

DAGNINO, R. e THOMAS, H. (1999) La Política Científica y Tecnológica en América Latina: nuevos escenarios y el papel de la comunidad de investigación. Redes. Buenos Aires: v. 6, n. 13, p.49-74.

DELIZOICOV, D. (1991) Conhecimento, Tensões e Transições. Tese de Doutoramento. São Paulo: FEUSP.

FOUREZ, G. (1995) A Construção das Ciências: Introdução à Filosofia e à Ética da Ciências.

${ }^{17[17]}$ Folha de São Paulo, 28/01/2001, A-15. 
São Paulo: Editora da UNESP.

FOUREZ, G. (1999) Alfabetización científica y tecnológica. Buenos Aires: Colihue.

FREIRE, P. (1992) Pedagogia da Esperança: Um Reencontro com a Pedagogia do Oprimido. Rio de Janeiro: Paz e Terra.

. (1987) Pedagogia do Oprimido. 17 ed. Rio de Janeiro: Paz e Terra.

- (1996) Pedagogia da Autonomia: Saberes necessários à prática educativa. 6 ed. Rio de Janeiro: Paz e Terra.

GANA, M. T. S. (1995) Reflexiones en torno a la tecnología: su diagnostico en la periferia. Tesis (Doutorado en lógica y filosofia). Valencia: Facultat de Filosofia y Psicología Departamento de Lógica y Filosofia/Universidade deValencia.

GÓMEZ, R. J. (1997) Progreso, determinismo y pesimismo tecnológico. Redes. Buenos Aires: v. 4 , n. 10, p.59-94.

HERRERA, A O. (2000) Civilização Ocidental não dá Respostas à Crise Atual. In: Amilcar Herrera: Um intelectual Latino-Americano. Dagnino, R. (org.). Campinas: UNICAMP/IG/DPCT.

LUJÁN LÓPES, J. L. et al. (1996) Ciencia, Tecnología y Sociedad: Una Introducción al Estudio Social de la Ciencia y la Tecnología. Madrid: TECNOS.

PACEY, A. (1990) La Cultura de la Tecnología. México: Fondo de Cultura Económica.

PERNANBUCO, M. M. C. (1993) Significações e Realidade: Conhecimento. In: Pontuschka, N. (org.) Ousadia no Diálogo. São Paulo: Edições Loyola.

ROSA, V. L. (2000) Genética humana e sociedade: conhecimentos, significados e atitudes sobre a ciência da hereditariedade na formação de profissionais da saúde. Florianópolis: CED/UFSC.

SACHS, I. (1996) Brasil e os Riscos da Modernidade. Ciência Hoje. Rio de Janeiro: v.20, n.119, p. $12-14$.

SANMARTíN, J. (1990) Tecnología y Futuro Humano. Barcelona: Anthropos.

SNYDERS, G. (1988) A Alegria na Escola. São Paulo: Manole.

THUILLIER, P. (1989) O Contexto Cultural da Ciência. Ciência Hoje. Rio de Janeiro, v.9, n.50, p.18-23.

WINNER, L. (1987) La ballena y el reactor: un búsqueda de los limites en la era de la alta tecnologia. Barcelona: Gedisa.

\section{Correspondência:}

Décio Auler

Rua Padre Domingos Nostro 6420

Bairro Arroio Grande, Santa Maria - RS

CEP: 97120 - 000

E-mail: auler@ce.ufsm.br 